\title{
Perancangan Media Pembelajaran Fisika Berbasis Android
}

\author{
M. Ikhbal ${ }^{1,}$, , Hari Antoni Musril ${ }^{1}$ \\ ${ }^{1}$ Pendidikan Teknik Informatika dan Komputer; IAIN Bukittinggi; Alamat, Jl. Gurun Aua, Kubang \\ Putiah, telp. (0752) 33136; e-mail: balebal13@yahoo.com, \\ hariantonimusril@iainbukittinggi.ac.id \\ * Korespondensi: e-mail: balebal13@yahoo.com
}

Diterima: 29 Juli 2020; Review: 18 November 2020; Disetujui: 02 Desember 2020

Cara sitasi: Ikhbal M, Musril HA. 2020. Perancangan Media Pembelajaran Fisik Berbasis Android. Information Management for Educators and Professionals. 5 (1): 15-24

Abstrak: Media pembelajaran merupakan sarana penyalur pesan atau informasi belajar yang hendak disampaikan oleh sumber pesan kepada sasaran atau penerima pesan tersebut. Penggunaan media pengajaran dapat membantu pencapaian keberhasilan belajar. Penelitian perancangan media pembelajaran fisika berbasis android di jurusan teknik komputer dan jaringan SMK Negeri 1 Tanjung Raya merupakan sebuah program bantu untuk memudahkan guru dalam menjelaskan pelajaran serta memudahkan siswa untuk memahami pelajaran yang di ajarkan. Jenis penelitian yang penulis gunakan adalah penelitian Research and Development (R\&D). Menggunakan model pengembangan versi 4-D (four $D$ ). 4D terdiri dari define, design, develop, dessiminatte. Model pengembangan sistemnya menggunakan model pengembangan multimedia Luther - Sutopo. Dari uji produk yang penulis lakukan memperoleh uji validitas dengan rata-rata nilai 0,85 yaitu valid, uji praktikalitas penulis mendapatkan rata-rata 0,92 dengan kategori sangat tinggi, dan pada uji efektivitas penulis mendapatkan rata-rata nilai 0,92, berdasarkan hasil uji produk ini, dapat membantu mahasiswa, guru atau dosen yang akan melakukan penelitian dalam bidang pendidikan agar penelitian dapat dilanjutkan untuk melihat keberhasilan penggunaan media ini kepada siswa dan para calon guru maupun guru dapat mengembangkan materi dari desain yang telah di rancang ini.

Kata Kunci : Adobe Flash CS6, Adobe Air, Android, Luther-Sutopo, Media Pembelajaran.

Abstract: Learning media is a means of channeling messages or learning information to be conveyed by the source of the message to the target or recipient of the message. The use of teaching media can help achieve successful learning The research design of Android-based physics learning media in the department of computer engineering and networking at SMK Negeri 1 Tanjung Raya is an assistive program to facilitate teachers in explaining lessons and make it easier for students to understand the lessons taught. The type of research the author uses is Research and Development (R\&D) research. Using the 4-D (four $D$ ) version development model. 4D consists of define, design, develop, dessiminatte. The system development model uses the Luther - Sutopo multimedia development model. From the product test that the author did, obtained a validity test with an average value of 0.85 that is valid, the practicality test of the writer got an average of 0.92 with a very high category, and on the effectiveness test the writer got an average value of 0.92 , based on the results of this product test, can help students, teachers or lecturers who will conduct research in the field of education so that research can be continued to see the successful use of this media to students and prospective teachers and teachers can develop material from this design that has been designed.

Keywords : Adobe Flash CS6, Adobe Air, Android, Luther-Sutopo, Learning Media. 


\section{Pendahuluan}

Media pembelajaran merupakan sarana penyalur pesan atau informasi belajar yang hendak disampaikan oleh sumber pesan kepada sasaran atau penerima pesan tersebut. Penggunaan media pengajaran dapat membantu pencapaian keberhasilan belajar [1]. Peranan media pembelajaran dalam proses belajar dan mengajar merupakan satu kesatuan yang tidak dapat dipisahkan dari dunia pendidikan. Media pembelajaran merupakan segala sesuatu yang dapat digunakan untuk menyalurkan pesan pengirim kepada penerima, sehingga dapat merangsang pikiran, perasaan, perhatian, dan minat peserta didik untuk belajar [1]. Penggunaan media dalam pembelajaran dapat membantu keterbatasan pendidik dalam menyampaikan informasi maupun keterbatasan jam pelajaran di kelas [2]. Keterlibatan media pembelajaran dalam proses pembelajaran diharapkan dapat mempengaruhi hasil belajar, semakin kongkrit pembelajaran yang diajarkan dan dirasakan oleh siswa maka pembelajaran semakin efektif [2].

Seorang pendidik dalam melaksanakan fungsi dan tugas dituntut untuk mempunyai seperangkat prinsip keguruan yaitu : (1) Kegairahan dan kesediaan untuk mengajar seperti memperhatikan; kesediaan, kemampuan, pertumbuhan, dan perbedaan peserta didik, (2) Membangkitkan gairah peserta didik, (3) Menumbuhkan bakat dan sikap peserta didik yang baik, (4) Mengatur proses belajar mengajar yang baik, (5) Memperhatikan perubahanperubahan kecendrungan yang mempengaruhi proses pembelajaran dan (6) Adanya hubungan manusiawi dalam proses pembelajaran [3]. Untuk memudahkan penyampaian ilmu pengetahuan seorang guru dapat menggunakan bantuan perangkat media pembelajaran [3].

SMK Negeri 1 Tanjung Raya adalah sekolah yang terletak di Kecamatan Tanjung Raya, Kabupaten Agam, Provinsi Sumatera Barat. Sekolah ini meiliki delapan Jurusan di antaranya Bisnis Kontruksi dan Properti (BKP), Desain Pemodelan dan Informasi Bangunan (DPIB), Teknik Instalasi Tenaga Listrik (TITL), Teknik Pendingin dan Tata Udara (TPTU), Teknik Pemesinan ( TM ), Teknik Kendaraan Ringan (TKR), Teknik Audio Video (TAV), Teknik Komputer dan Jaringan (TKJ), TKJ adalah salah satu jurusan di SMK Negeri 1 Tanjung Raya yang memiliki 7 kelas diantaranya 3 kelas untuk kelas 3, 2 kelas untuk kelas 2 dan 2 kelas untuk kelas 1, penulis memilih jurusan Teknik Komputer dan Jaringan (TKJ) dikarenakan sesuai dengan program studi penulis yaitu PTIK yang sangat relevan dengan TKJ.

SMK Negeri 1 Tanjung Raya Pada mata pelajaran fisika masih menggunakan metode pembelajaran mengajar diantaranya tanya jawab, diskusi dan ceramah. Guru mengalami kesulitan dalam menyampaikan rumus - rumus fisika dan penerapannya dalam soal, siswa juga mengalami kesulitan dimana siswa kurang paham menerapkan materi pembelajaran dalam kehidupan sehari hari. Guru mengalami kesulitan dalam menjelaskan konsep ke dalam analisa dan pikiran siswa dikarenakan guru hanya menggunakan media gambar yang dibuat dalam kertas dan ditempel di papan tulis. Siswa mengalami kesulitan dalam metode pembelajaran yang digunakan guru dalam mengajar yaitu metode ceramah, dimana terkadang mereka paham apa yang diajarkan terkadang tidak. Siswa lebih tertarik apabila media yang digunakan berbasis animasi computer, dan penulisa juga mendapatkan data bahwasan nya semua siswa kelas $X$ Jurusan TKJ memiliki smartphone android, dan berdasarkan pengalaman penulis disana, bahwa jaringan internet disana sudah bagus dan di tambah fasilitas Wifi di sekolah yang juga sudah memadai.

\section{Metode Penelitian}

Metode penelitian yang digunakan dalam penelitian adalah penelitian dan pengembangan atau Research and Development $(R \& D)$. $R \& D$ adalah metode penelitian yang digunakan untuk menghasilkan produk tertentu dan menguji keefektifan metode tersebut. Dalam bidang pendidikan, penelitian dan pengembangan merupakan metode penelitian yang digunakan untuk mengembangkan atau memvalidasi produk-produk yang digunakan dalam pendidikan dan pembelajaran. Dari uraian tersebut maka dapat ditarik kesimpulan bahwa Research and Development (R\&D) adalah metode penelitian yang bertujuan untuk menghasilkan produk-produk tertentu serta menguji validitas dan keefektifan produk tersebut dalam penerapannya [4]. Jenis penelitian yang digunakan adalah penelitian dan pengembangan Research and Development (R\&D) versi 4D. Tahapan penelitian pengembangan model 4D dikembangkan oleh Thiagarajan. Model 4D ini terdiri dari 
pendefenisian (define), perancangan (design), pengembangan (develop), dan penyebaran/uji coba (disseminate) [5].

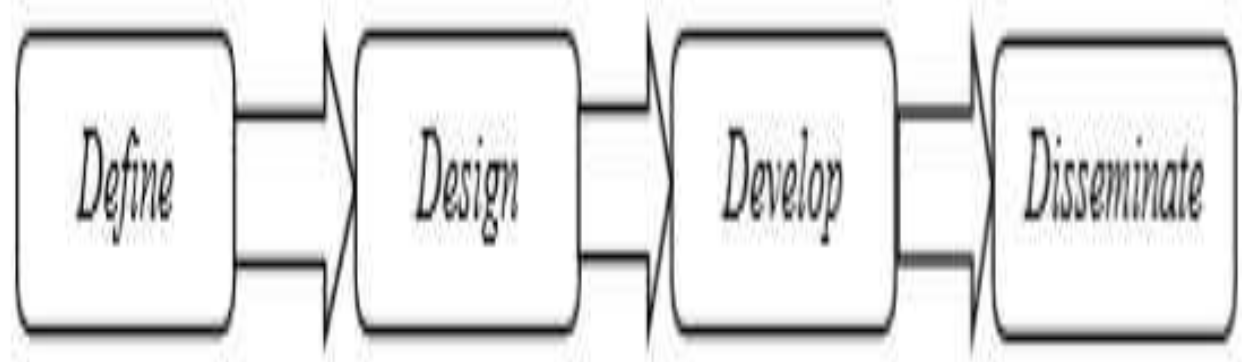

Sumber: H. A. Musril, Jasmienti, and M. Hurrahman (2020)

Gambar 1. Pengembangan Model 4D

\subsection{Model Pengembangan Media}

Penelitian ini menggunakan model pengembangan multimedia Luther - Sutopo. Model pengembangan multimedia Luther-Sutopo terdiri dari enam tahap yaitu konsep, desain, pengumpulan bahan, assembly (pembuatan), testing dan distribusi [7].

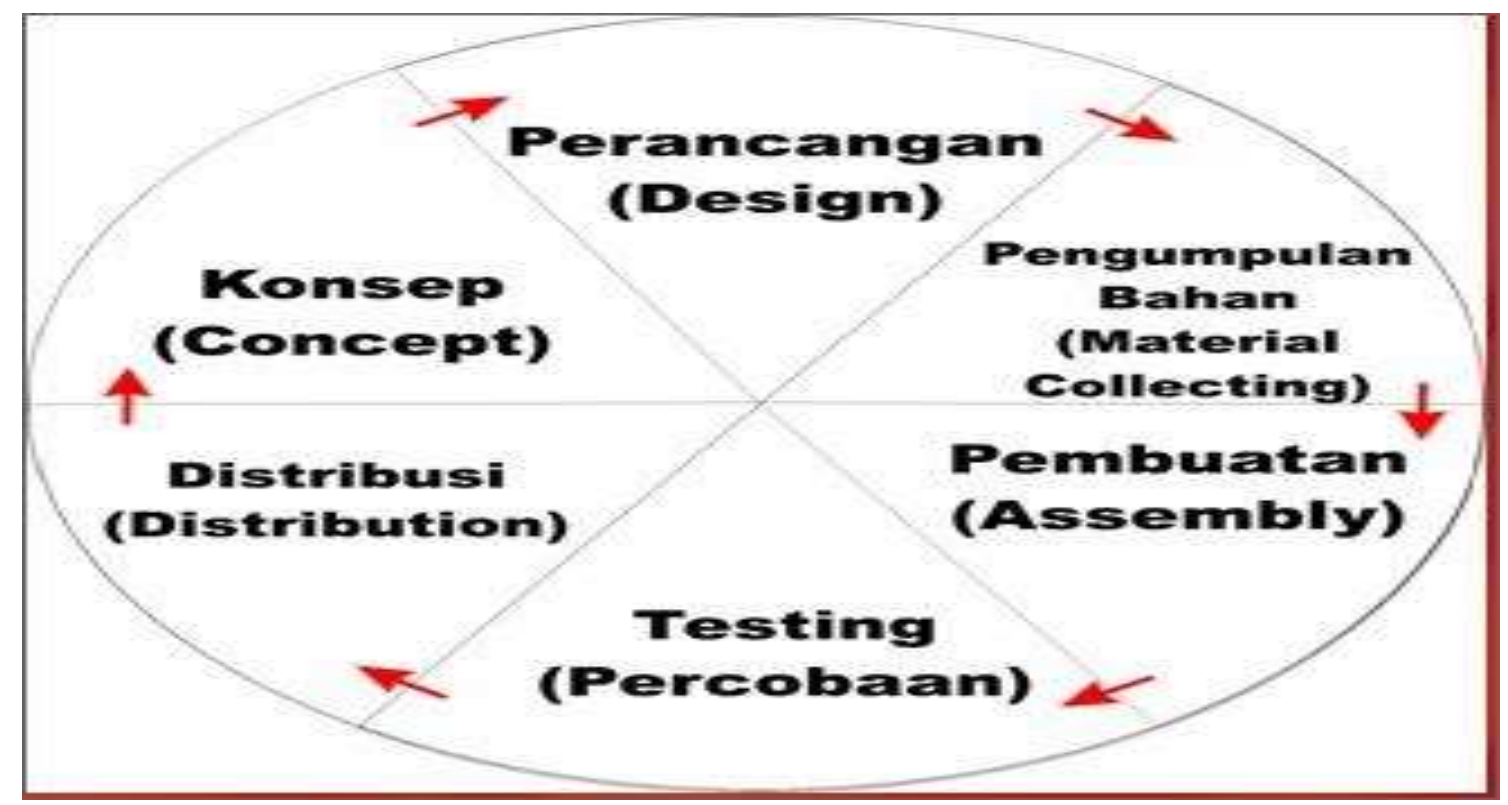

Sumber: E. Yosrita and R. Cahyaningtyas (2014)

Gambar 2. Model Pengembangan Multimedia Luther-Sutopo

\subsection{Tahapan Penelitian}

Tahapan penelitian yang penulis laksanakan yaitu mengkolaborasikan metode $R \& D$ versi 4-D dan model pengembangan multimedia Luther - Sutopo. Tahapan penelitian yang dilakukan dapat dilihat pada gambaran di bawah ini : 


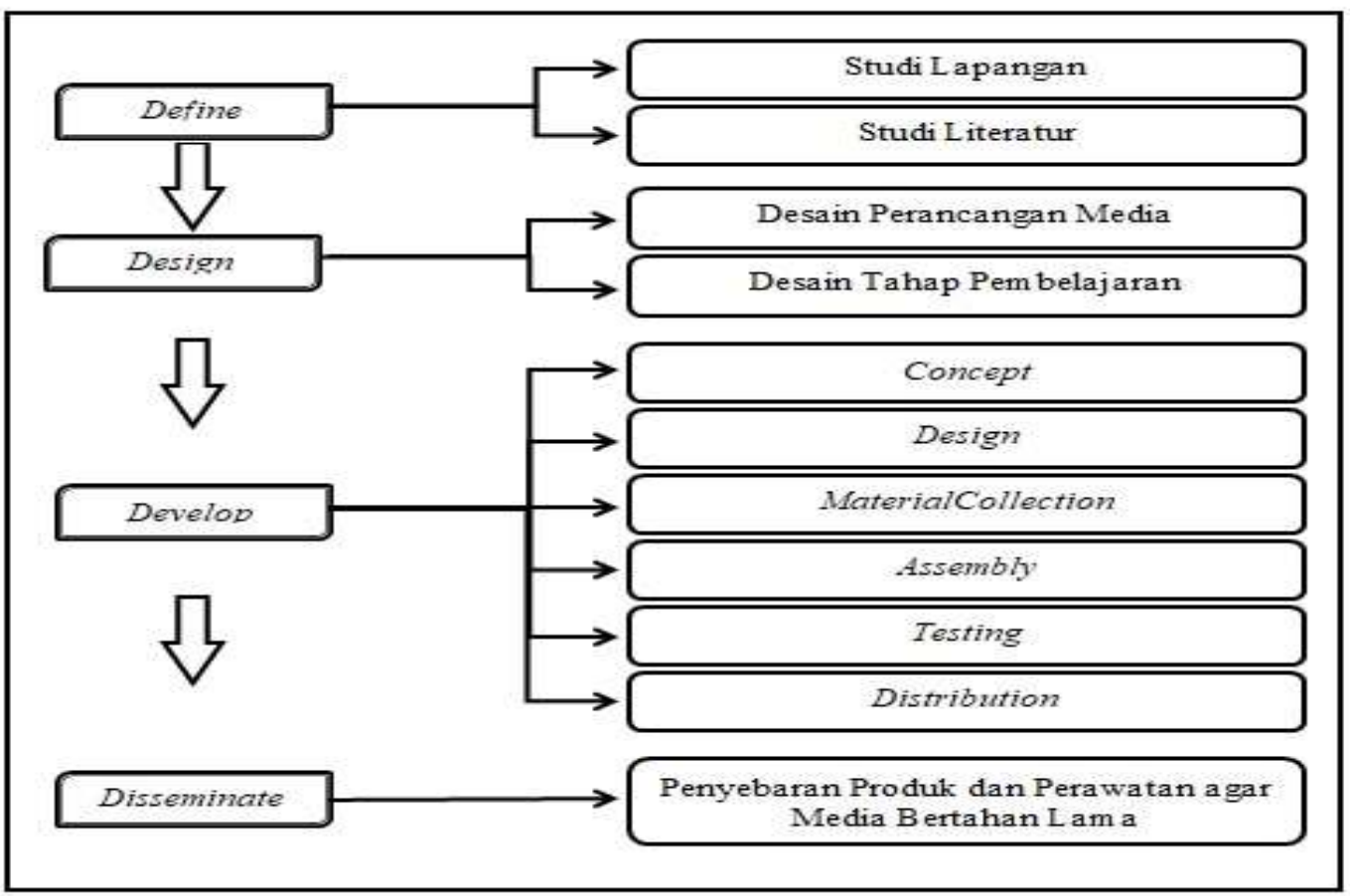

Sumber: Hasil penelitian (2020)

Gambar 3. Skema Tahapan Penelitian

\subsection{Rumus Uji Produk}

Hasil angket uji validitas proudk diolah dengan mengacu rumus Statistik Aiken's $V$ sebagai berikut [8].

$$
V=\sum \mathrm{s} /[\mathrm{n}(\mathrm{c}-1)]
$$

Keterangan :

$S:$ r-lo

Lo : Angka penelitian validitas yang terendah

$C$ : Angka penelitian validitas yang tertinggi

$R$ : Angka yang diberikan oleh seorang penilaian

$N$ : Jumlah nilai

Tabel 1. Kriteria Penentuan Validitas Aiken's V [8]

\begin{tabular}{c|c}
\hline Persentase $\%$ & Kriteria \\
\hline $0,6<$ & Tidak Valid \\
\hline$>=0,6$ & Valid \\
\hline
\end{tabular}

Sumber: S. Derta (2019)

\subsection{Uji Praktikalitas Produk}

Hasil angket uji praktikalitas produk dianalisis menggunakan moment kappa, sebagai berikut [9]:

$$
K=\frac{p-p e}{1-p e}
$$

Keterangan :

$K$ : moment kappa yang menunjukkan tingkat kepraktisan produk

$P \quad$ : Proporsi yang terealisasi, dihitung dengan cara jumlah nilai yang diberikan oleh penguji dibagi jumlah maksimal

$P e$ :Proporsi yang tidak terealisasi, dihitung dengan cara jumlah nilai maksimal dikurangi dengan jumlah total yang diberi penguji dibagi jumlah nilai maksimal. 
Tabel 2. Kriteria Penentuan Praktikalitas Moment Kappa [9]

\begin{tabular}{c|c}
\hline Interval & Kategori \\
\hline $0,81-1,00$ & Sangat tinggi \\
\hline $0,61-0,80$ & Tinggi \\
\hline $0,41-0,60$ & Sedang \\
\hline $0,21-0,40$ & Rendah \\
\hline $0,01-0,20$ & Sangat Rendah \\
\hline$\leq 0,00$ & Tidak praktis \\
\hline
\end{tabular}

Sumber: R. Sagita, F. Azra, and M. Azhar (2017)

\subsection{Uji Efektifitas Produk}

Hasil angket uji efektifitas dianalisa dengan mengacu rumus statistik Richard R. Hake (GScore) sebagai berikut [10]:

$$
<g>=\frac{(\%<S f>-\%<S i>)}{(100-\%<S i>)}
$$

Keterangan:

$<g>$ : G-Score

$<S t>$ : Score akhir

$<$ Si> : Score awal

Kriteria setiap indikator dari lembar uji sebagai berikut [10] : (1). "High-g" efektifitas tinggi jika mempunyai $(<g>)>0.7$; (2). "Medium-g" efektifitas sedang jika mempunyai $0.7>(<g>)>0.3$; (3). "Low- $g$ " efektifitas rendah jika mempunyai $(<g>)<0.3$.

\section{Hasil dan Pembahasan}

Hasil dari penelitian ini adalah sebuah media pembelajaran fisika berbasis android. Media pembelajaran ini bisa digunakan di perangkat android dengan menggunakan aplikasi pendukung yaitu Adobe AIR. Penulis telah melakukan uji media pembelajaran tersebut ke ahli komputer maupun pendidikan beserta pihak sekolah. Hasil yang penulis dapatkan yaitu media pembelajaran yang penulis buat valid nilainya 0,85 , praktikalitas nilainya 0,92 dan efektivitas nilainya 0,92 untuk digunakan di SMK Negeri 1 Tanjung Raya.

Pembahasan dari kegiatan penelitian adalah sebagai berikut: (1). Define, Pada tahap ini penulis melakukan mencari informasi mengenai media pembelajaran di SMK Negeri 1 Tanjung Raya. Penulis juga mencari permasalahan apa yang dihadapi oleh guru dan siswa pada saat proses pembelajaran di SMK Negeri 1 Tanjung Raya. (2). Design, Dalam tahap perancangan, peneliti sudah menyiapkan kerangka konseptual, model media pembelajaran, dan perangkat pembelajaran berupa KI \& KD materi pembelajaran, untuk di aplikasikan ke dalam media pembelajaran.

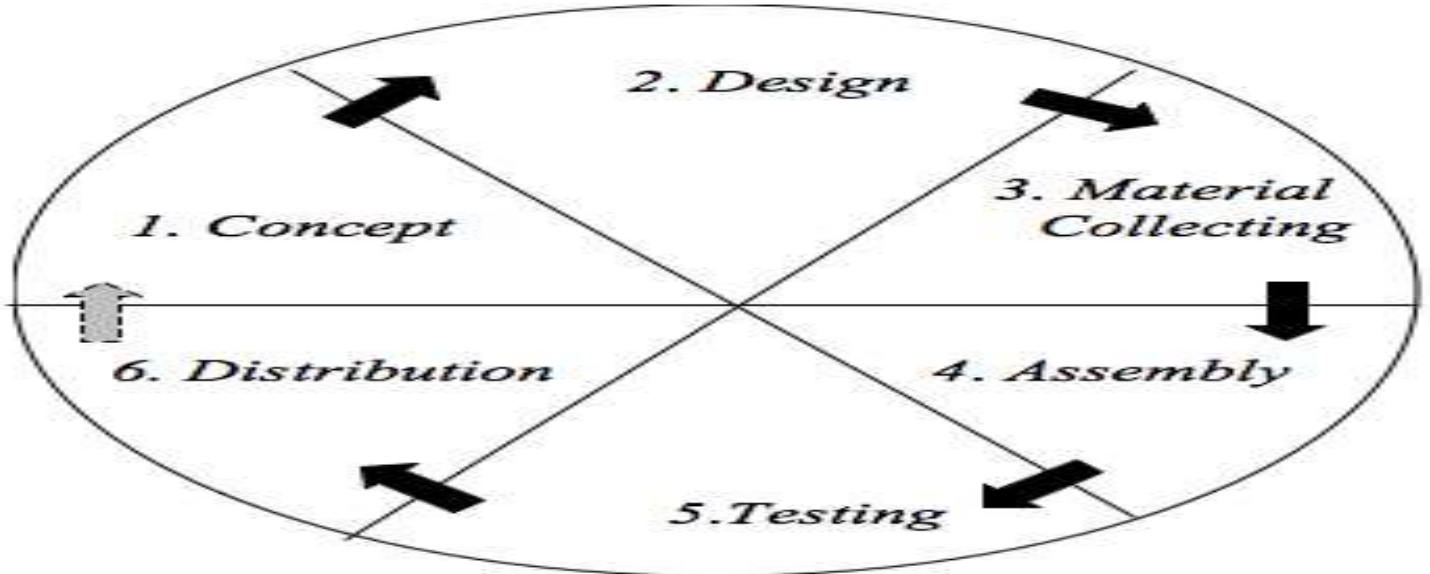

Sumber: E. Yosrita and R. Cahyaningtyas (2014)

Gambar 4. Model Pengembangan 
Develop terdiri dari: a). Concept yaitu perancangan media pembelajaran ini hasil dari produk yang di hasilkan nya berupa Apk, dan bisa di instal di smartphone akan tetapi sebelum nya kita harus menginstal dulu aplikasi pendukunya yaitu Adobe $A I R$ agar bisa di jalankan di smartphone. Penyajian media pembelajaran ini menggunakan suara, gambar - gambar yang menarik serta kombinasi beberapa warna sehingga dapat menarik perhatian siswa. Media pembelajaran ini juga di lengkasi soal - soal untuk menguji sejauh mana pemahaman siswa akan materi yang di ajarkan. b). Design yaitu ada tahap ini di lakukan perancangan struktur Navigasi, Storyboard dan user interface.

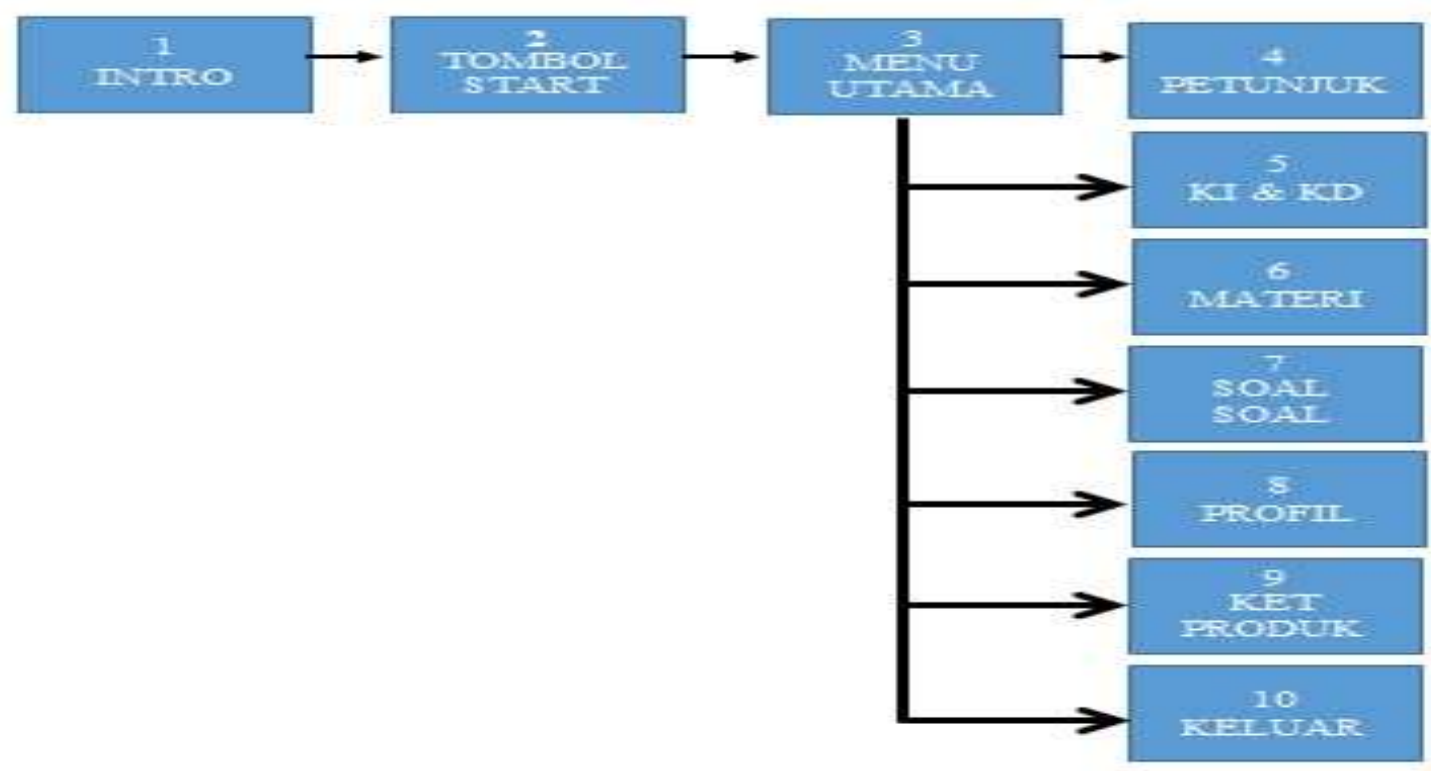

Sumber: Hasil penelitian (2020)

Gambar 5. Struktur navigasi menu utama

Dalam struktur navigasi materi dimulai dari halaman intro, kemudian masuk ke menu utama lalu ada menu materi, dalam menu materi akan di tampilkan menu bab 1- bab 5 seperti digambarkan pada gambar 6 dibawah ini.

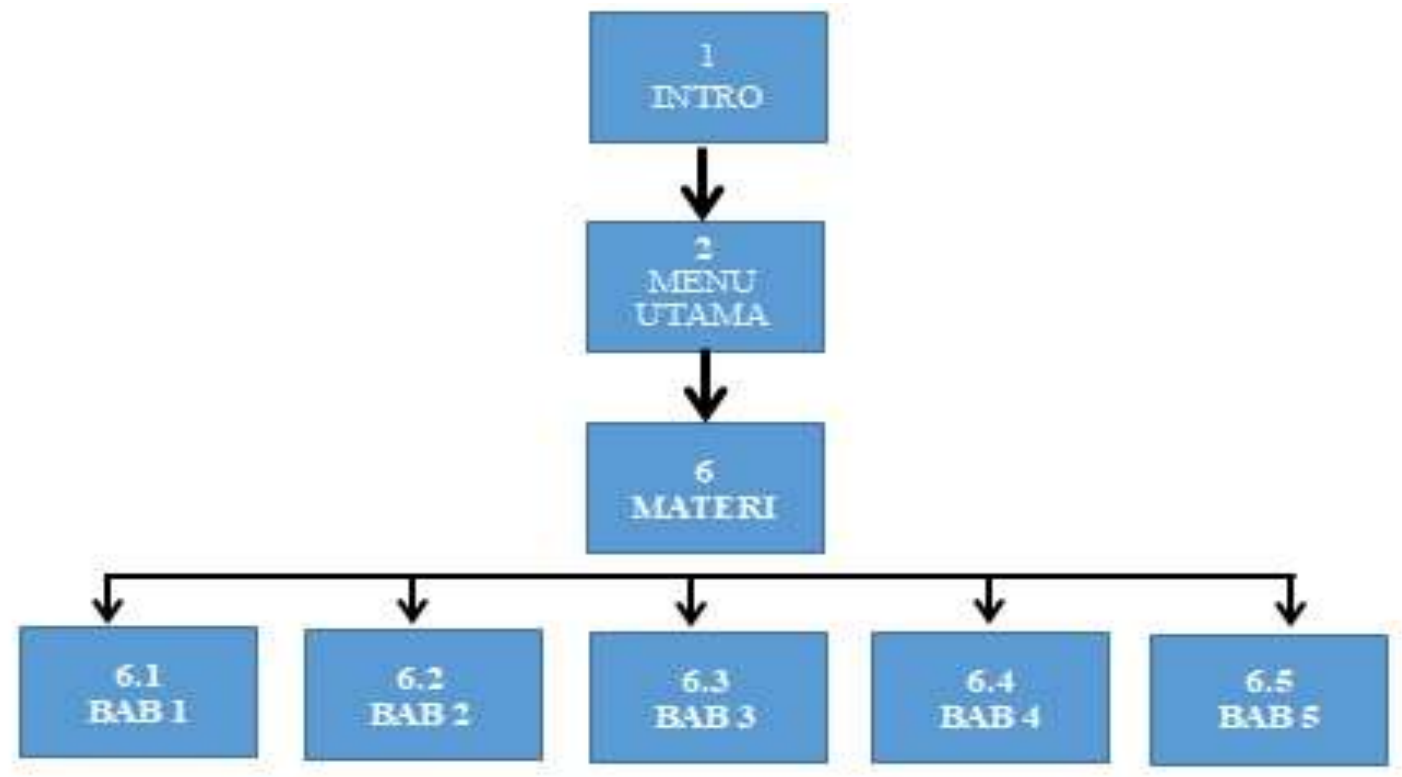

Sumber: Hasil penelitian (2020)

Gambar 6. Struktur navigasi Materi

Perancangan Storyboard secara ringkas untuk setiap scene dapat dilihat pada table di bawah : 
Vol. 5, No. 1, Desember 2020, 15-25

Table 3. Storyboard Ringkas

\begin{tabular}{l|c}
\multicolumn{1}{c}{ Daftar Scane } & Isi Scane \\
\hline Scane 1 & INTRO \\
\hline Scane 2 & MENU UTAMA \\
\hline Scane 15 & PETUNJUK \\
\hline Scane 43 & KI \& KD \\
\hline Scane 3 & MATERI \\
\hline Scane 9 & SOAL SOAL \\
\hline Scane 42 & PROFIL \\
\hline Scane 44 & KET PRODUK \\
\hline Scane 2 & KELUAR \\
\hline Sumber: Hasil Penelitian (2020)
\end{tabular}

Sumber: Hasil penelitian (2020)

Berikut adalah contoh rancangan antar muka dari aplikasi ini:

Tabel 4. Rancangan Antar Muka Aplikasi

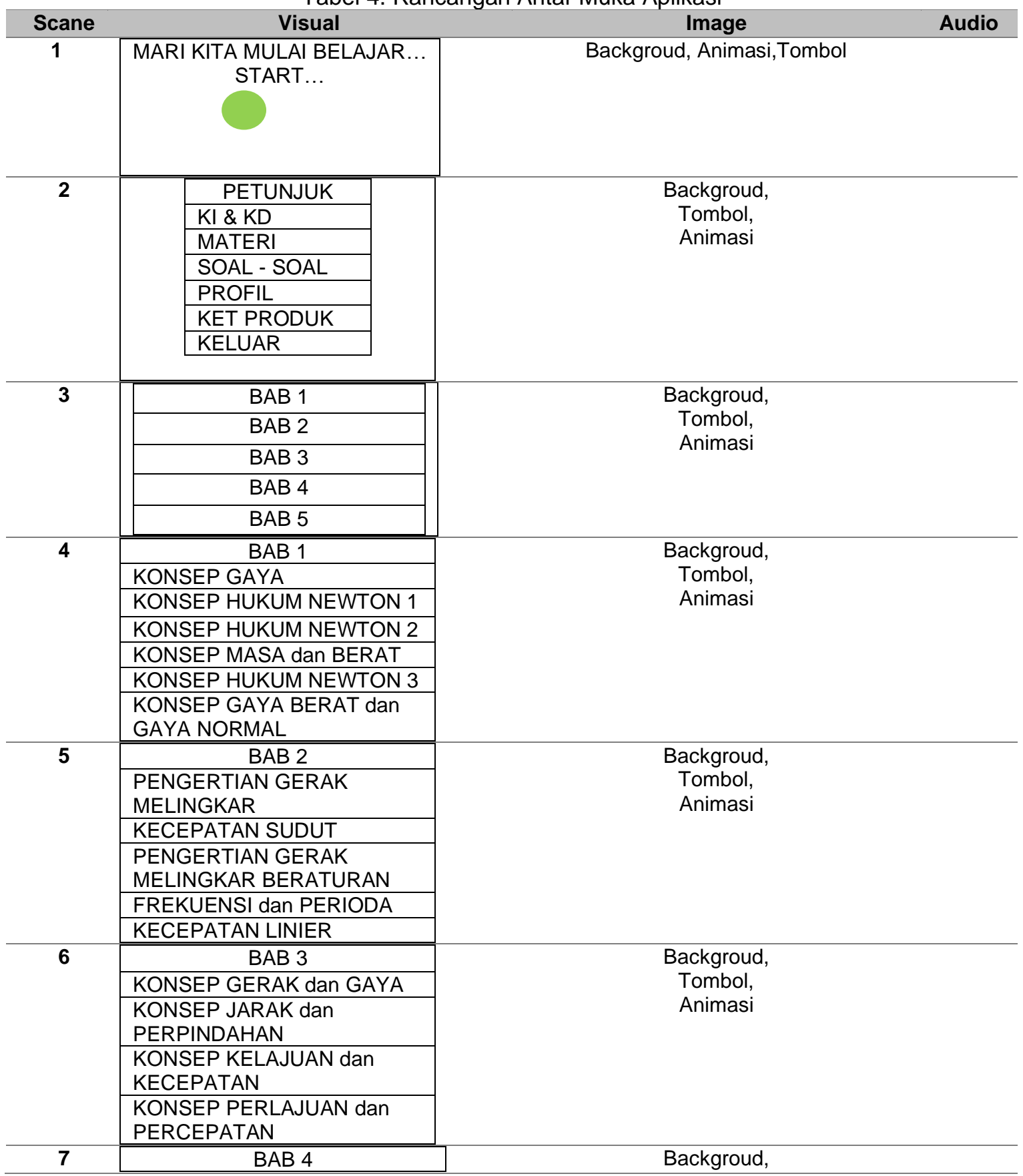




\begin{tabular}{|c|c|c|c|}
\hline Scane & Visual & Image & Audio \\
\hline & $\begin{array}{l}\text { PENGERTIAN BESARAN dan } \\
\text { SATUAN }\end{array}$ & \multirow[t]{6}{*}{$\begin{array}{l}\text { Tombol, } \\
\text { Animasi }\end{array}$} & \\
\hline & $\begin{array}{l}\text { PENGERTIAN BESARAN } \\
\text { POKOK dan TURUNAN }\end{array}$ & & \\
\hline & $\begin{array}{l}7 \text { BESARAN POKOK DALAM } \\
\text { SI, BESERTA SATUAN dan } \\
\text { LAMBANG DIMENSINYA }\end{array}$ & & \\
\hline & KONVERSI SATUAN & & \\
\hline & $\begin{array}{l}\text { JENIS - JENIS ALAT UKUR } \\
\text { PANJANG, MASA, dan WAKTU }\end{array}$ & & \\
\hline & $\begin{array}{l}\text { CARA MEMBACA ALAT UKUR } \\
\text { PANJANG }\end{array}$ & & \\
\hline \multirow[t]{5}{*}{8} & BAB 5 & \multirow{5}{*}{$\begin{array}{l}\text { Backgroud, } \\
\text { Tombol, } \\
\text { Animasi }\end{array}$} & \\
\hline & $\begin{array}{l}\text { MASA JENIS dan BERAT } \\
\text { JENIS }\end{array}$ & & \\
\hline & ELASTISITAS & & \\
\hline & TEGANGAN & & \\
\hline & REGANGAN & & \\
\hline
\end{tabular}

Sumber: Hasil penelitian (2020)

\section{Material Collecting}

Material Collecting adalah tahap pengumpulan bahan. Bahan yang di kumpulkan adalah image atau gambar, audio, foto digital, background, Gif, dan image-image pendukung lain nya. Pada praktiknya, tahap ini bisa dilakukan secara paralel dengan tahap assembly.

\section{Assembly}

Assembly adalah tahap pembuatan seluruh objek multimedia berdasarkan perancangan yang telah di lakukan sebelumnya.

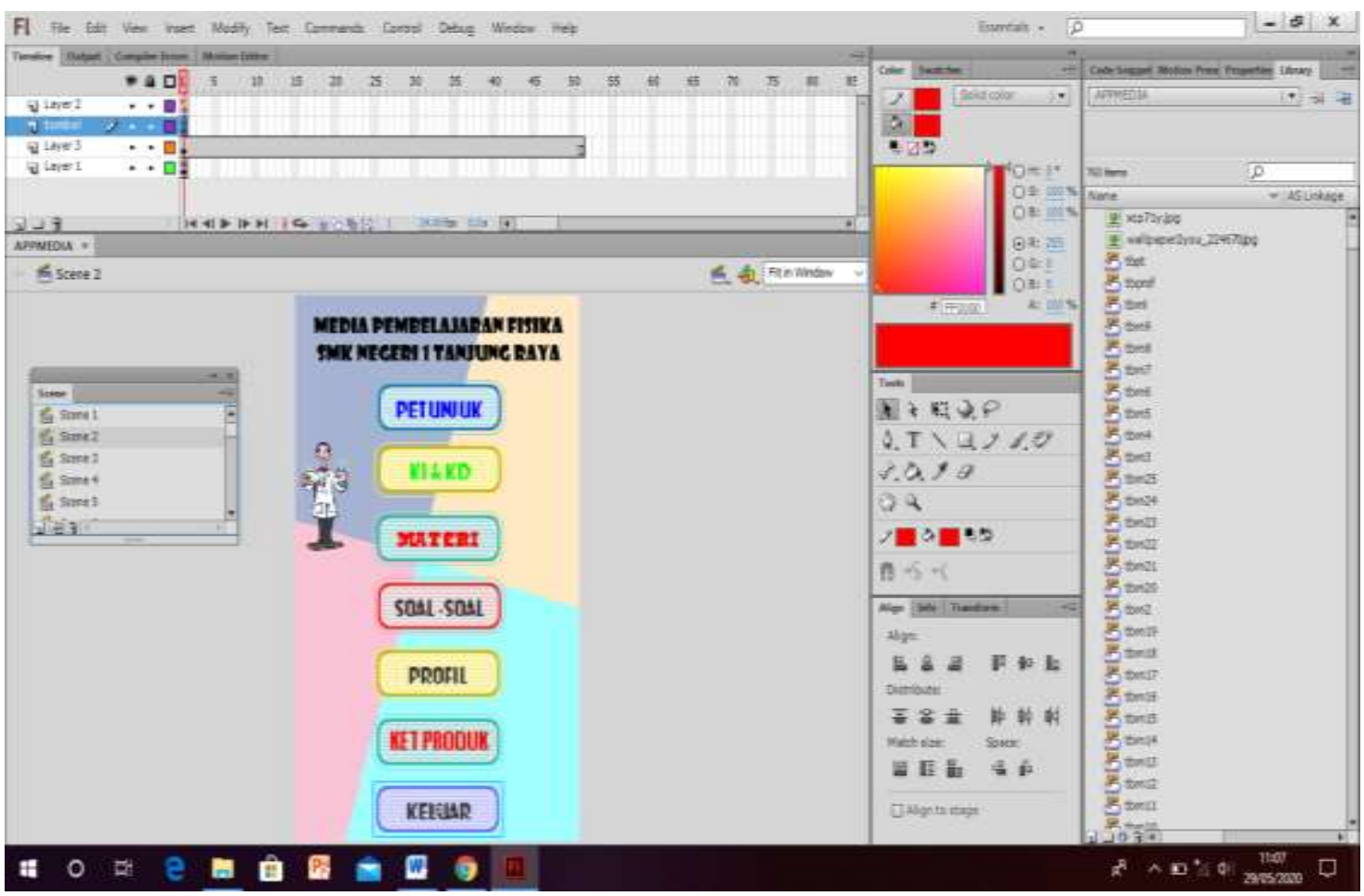

Sumber: Hasil penelitian (2020)

Gambar 7. Tombol Navigasi

\section{Testing}


Setelah tahap pembuatan media pembelajaran selesai, tahap selanjutnya adalah melakukan test terhadap media pembelajaran dengan tujuan untuk mengetahui apakah aplikasi media pembelajaran ini dapat berjalan dengan baik atau tidak.

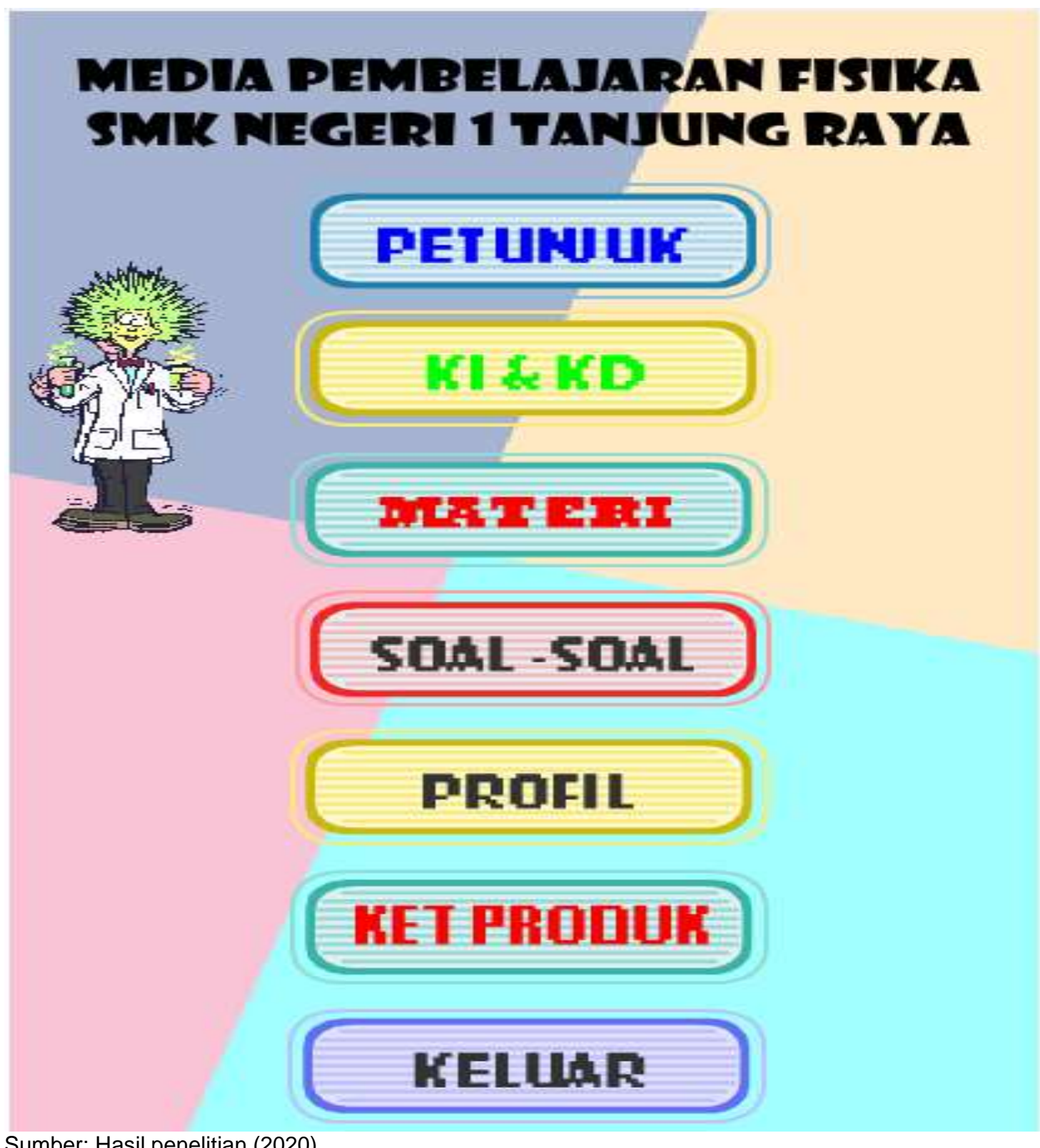

Sumber: Hasil penelitian (2020)

Gambar 8. Tampilan Intro

\section{Distribution}

Dalam proses ini aplikasi yang sudah jadi di salin ke Device Android pengguna, Ialu dilakukan pemasangan (instal). Selesai pemasangan pengguna diwajibkan untuk memasang aplikasi Adobe AIR supaya aplikasi media pembelajaran ini bisa di jalankan di smartphone.

\section{Disseminate}

Untuk tahap awal ini penyebaran media pembelajaran ini hanya di lakukan kepada guru fisika kelas X TKJ SMK Negeri 1 Tanjung Raya. Hal ini dimaksudkan karena dalam prosesnya nanti media ini akan mengalami banyak perbaikan berdasarkan saran dan masukan dari pikah terkait, baik dari Dosen, Guru Fisika kelas X SMK Negeri 1 Tanjung Raya, maupun ahli ahli yang telah menguji validitas, praktikalitas dan efektifitas dari media pembelajaran. 


\section{Kesimpulan}

Perancangan media pembelajaran berbasis android pada mata pelajaran fisika ini di rancang dan di desain dengan menggunakan Software Adobe Flash CS6 sebagai Software utama dan di dukung oleh Software lainnya. Media ini telah selesai di rancang dalam bentuk file Apk. Yang dapat di instal di Smartphone Android, untuk menjalankan aplikasi, pengunaka juga harus menginstal Adobe AIR. Dalam merancang media ini penulis menggunaka metode R\&D versi 4-D dan model pengembangan multimedia Luther - Sutopo yang terdiri dari Concept, Design, Material Collection, Assembly, Testing dan Distribution. Adapun media pembelajaran android ini terdiri dari : Petunjuk, KI \& KD, Materi, Soal - Soal, Profil, Ket Produk, Keluar.

\section{Referensi}

[1] T. Tafonao, "Peranan Media Pembelajaran Dalam Meningkatkan Minat Belajar Mahasiswa," J. Komun. Pendidik., vol. 2, no. 2, pp. 103-114, 2018.

[2] A. N. Khomarudin, L. Efrianti, and M. Tafsir, "Pengembangan Media Pembelajaran Mobile Learning Berbasis Android Pada Mata Kuliah Kecerdasan Buatan," J. Educ., vol. 3, no. 1, pp. 1-87, 2018.

[3] Rohmani, W. Sunarno, and Sukarmin, "Pengembangan Media Pembelajaran Fisika Berbasis Multimedia Interaktif Terintegrasi Dengan Lks Pokok Bahasan Hukum Newton Tentang Gerak Kelas X SMA/MA," J. Inkuiri, vol. 4, no. 1, pp. 152-162, 2015.

[4] Hanafi, "Konsep Penelitian R \& D Dalam Bidang Pendidikan," J. Kaji. Keislam., vol. 4, no. 2, pp. 129-150, 2017.

[5] H. A. Musril, Jasmienti, and M. Hurrahman, "Implementasi Teknologi Virtual Reality Pada Media Pembelajaran Perakitan Komputer," JANAPATI J. Nas. Pendidik. Tek. Inform., vol. 9, pp. 83-95, 2020.

[6] R. R. Fadila, W. Aprison, and H. A. Musril, "Perancangan Perizinan Santri Menggunakan Bahasa Pemograman PHP / MySQL Di SMP Nurul Ikhlas," CSRID, vol. 11, no. 2, pp. 84-95, 2019.

[7] E. Yosrita and R. Cahyaningtyas, "Penerapan Metode Pengembangan Multimedia Luther-Sutopo Pada Pengembangan Aplikasi Simulasi Untuk Menghitung Determinan Matrik," J. IIm. Fifo, vol. 6, no. 1, pp. 23-29, 2014.

[8] S. Derta, "Perancangan Sistem Informasi Pengelolaan Praktik Kerja Lapangan (PKL) di SMK Negeri 2 Bukittinggi," J. Sains, Inform. dan Ekon., vol. 2, no. 2, pp. 79-86, 2019.

[9] R. Sagita, F. Azra, and M. Azhar, "Pengembangan Modul Konsep Mol Berbasis Inkuiri Terstruktur Dengan Penekanan Pada Interkoneksi Tiga Level Representasi Kimia Untuk Kelas X SMA," J. Ekstra Pendidik., vol. 1, no. 2, pp. 25-32, 2017.

[10] R. R. Hake, "Analyzing change/gain scores," Educ. Psychol. Meas., 1985. 